\title{
Nature of light rain during presence and absence of bright band
}

\author{
Mahen Konwar*, R S Maheskumar, S K Das and S B Morwal \\ Indian Institute of Tropical Meteorology, Pune 411 008, India. \\ ${ }^{*}$ Corresponding author.e-mail: mkonwar@tropmet.res.in
}

This paper reports the evolution of rain drop size distribution (DSD) during bright band (BB) and noBB (NBB) conditions of low intensity rainfall events as observed by a vertically pointing Micro Rain Radar (MRR) over Pune $\left(18.58^{\circ} \mathrm{N}, 73.92^{\circ} \mathrm{E}\right)$, India. The BB is identified by enhanced radar reflectivity factor $Z$ (dBZ) at the $0^{\circ} \mathrm{C}$ isotherm. The gradient of hydrometeor fall velocity is found to be a good indicator in identifying the melting layer when enhanced radar reflectivity at melting layer is not prominent. The storm structures as observed by the MRR are compared with CloudSat observations that provide evidence of ice hydrometeor at $\sim-60^{\circ} \mathrm{C}$ with clear indication of $\mathrm{BB}$ at $0^{\circ} \mathrm{C}$. Storm heights at warmer than $0^{\circ} \mathrm{C}$ are evident during NBB conditions from CloudSat. This suggests that warm rain processes are responsible for producing rain during NBB conditions. During BB conditions, bimodal DSDs below the melting layer are observed at lower altitudes. The DSDs of shallow warm precipitating systems of NBB conditions are monomodal at all the altitudes. Significantly, normalized DSDs are found to be bimodal for BB conditions, and monomodal for NBB conditions which confirm different dominant microphysical processes. It is found that the observed bimodal DSDs during BB conditions are mainly due to the collision, coalescence and break-up processes. During NBB conditions, number and size of large raindrops grow while reaching the ground without much breakup. The radar reflectivity and rainfall intensity $R\left(\mathrm{mmh}^{-1}\right)$ relationship of the form $Z=a R^{b}$ are found out for BB and NBB conditions. Existing different microphysical processes lead to large coefficient in the $Z-R$ relationship with small exponent during BB conditions while during NBB conditions the coefficients are small with large exponents.

\section{Introduction}

Light rain occurs persistently and steadily for several hours even for many days during monsoon season over India. It covers large area and contributes heavily towards the net rainfall in the tropics (Houze 1997). Such rain, namely stratiform rain can be identified from radar observations by enhanced radar reflectivity factor $Z$ (dBZ) known as the bright band (BB) signature where large aggregation and melting of hydrometeors take place near the $0^{\circ} \mathrm{C}$ isotherm (Austin and Bemis 1950; Battan 1973; Stewart et al. 1984; Klaassen 1988; Willis and Heymsfield 1989; Fabry and Zawadzki 1995; Huggel et al. 1996; Houze 1997; Steiner and Smith 1998; Glickman 2000; Gray et al. 2001; White et al. 2003; Zawadzki et al. 2005). Presence of large gradient of hydrometeor, Doppler velocity and turbulence accompanied by enhanced radar reflectivity at the melting layer also indicate

Keywords. Precipitation; stratiform; bright band; microphysics. 
stratiform rain (Williams et al. 1995). It is characterized by weak vertical air velocity comparable to the fall velocity of snow (Houze 1993, 1997). Light rain is reported to fall from another type of nonconvective rains, during no $\mathrm{BB}$ (NBB) conditions with orographically forced condensation and coalescence process (White et al. 2003; Martner et al. 2008). Such nonconvective rain is reported both at coastal mountains of Cazadero, California (White et al. 2003; Martner et al. 2008) and California flat valley (Kingsmill et al. 2006). Over coastal and hilly stations in Kerala, India, rainfall frequency is mostly dominated by low intensity rainfall that occurs from $65 \%$ to $90 \%$ of time (Sasi Kumar et al. 2007). In this work, we utilized rain drop size distribution (DSD) and rain parameters to study microphysical properties of light rain collected from a vertically pointing Micro Rain Radar (MRR) (Löffler-Mang et al. 1999; Peters et al. 2002) located at Pune, India.

The microphysical processes taking place aloft are responsible for the DSDs observed on ground. The equilibrium between coalescence and collisional breakup processes may result so-called equilibrium DSDs during initial convective rain over a brief period of time (List 1988; Zawadzki and Antonio Agostinho 1988; Atlas and Ulbrich 2000; Jameson and Kostinski 2000; Atlas and Williams 2003; Steiner et al. 2004). During stratiform rain, microphysical processes such as particle growth by vapour diffusion, aggregation of snowflakes thereafter melting processes result large raindrops (Tokay and Short 1996; White et al. 2003; Sharma et al. 2009). Kirankumar et al. (2008) found that the growth and decay of raindrops may be minimum implying nominal variation in the DSD gamma parameters. In case of nonconvective rain of NBB conditions, the DSDs are characterized by greater number of small drop concentration and smaller concentrations of large drops in comparison to the DSDs of BB conditions (Martner et al. 2008). The stratiform rain DSD follows classical exponential distribution (Marshall and Palmer 1948). However, the normalized DSD shapes for different rain categories found to depart from analytical shapes such as exponential, gamma, lognormal and modified gamma DSDs (Testud et al. 2001). By normalizing the DSD, one can find the shape of the distributions irrespective of different liquid water content LWC $\left(\mathrm{gm}^{-3}\right)$ and rainfall intensity $R\left(\mathrm{mmh}^{-1}\right)$. They suggested dominant physical mechanisms that constraint the shape of DSD towards a 'universal' shape. Following Testud et al.'s (2001) method, Konwar et al. (2006) reported a 'universal' shape of normalized rain DSDs both for low $\left(R<10 \mathrm{mmh}^{-1}\right)$ and high rainfall intensities $\left(R>10 \mathrm{mmh}^{-1}\right)$ categories over a tropical station Gadanki, India.

Convective and stratiform type of rain results different radar reflectivity factor and rain fall intensity relations of the form $Z=a R^{b}$. Physically the coefficient ' $a$ ' and exponent ' $b$ ' reflect the microphysical processes undergone aloft during precipitation (Steiner and Smith 1998). Presence of large raindrops during stratiform rain results size controlled DSDs that can be inferred from the large exponent value in the $Z-R$ relationship. During convective rain collisional-breakup processes are dominant, referred to as number controlled process which can be realized from the near unity value of exponent in $Z-R$ relationship (Steiner et al. 2004). For detailed discussion on the number and size controlled processes of DSDs, readers are referred to Steiner et al. (2004). Variations of $Z-R$ relationships from event to event and even within an event indicate different microphysical processes (Atlas et al. 1999; Sharma et al. 2009). Though during stratiform rain the rainfall intensity does not vary in large number, large variations in the coefficient and exponent values of $Z-R$ relationships are reported so far. Literature reveals that the coefficient ' $a$ ' varies from 44 to 865 while the exponent ' $b$ ' varies from 0.97 to 1.90 (Atlas et al. 1999; Rao et al. 1999, 2001; Maki et al. 2001; Ulbrich and Atlas 2007; Martner et al. 2008; Sharma et al. 2009). Such wide variations of these parameters point towards different microphysical processes taking place aloft.

We explored here the microphysical processes responsible for rain DSDs during presence and absence of BB conditions of widespread low intensity rain events. The normalized DSDs at different altitudes during the presence and absence of $\mathrm{BB}$ conditions are also examined. We provide a plausible explanation for the observed large variations of the coefficients and exponents of $Z-R$ relationships during these widespread low intensity rain events. This paper is organized as follows: section 2 contains the system descriptions and data analysis, while section 3 consists of the result of this study and discussions. Lastly, the results are discussed in section 4 .

\section{Systems and data analysis}

The MRR utilized here is installed at the Indian Institute of Tropical Meteorology (IITM), Pune, India. It operates at $24.1 \mathrm{GHz}$ corresponding to a wavelength of $1.25 \mathrm{~cm}$. The system specification is provided in table 1 . It provides vertical profiles of number density $N(D)\left(\mathrm{m}^{-3} \mathrm{~mm}^{-1}\right)$ in diameter $(D)$ range between 0.4 and $4.9 \mathrm{~mm}, R\left(\mathrm{mmh}^{-1}\right)$, rain LWC $\left(\mathrm{g} \mathrm{m}^{-3}\right)$, fall velocity of hydrometeors $V$ 
Table 1. System specifications of micro rain radar-2.

\begin{tabular}{ll}
\hline Wavelength & $1.25 \mathrm{~cm}$ \\
Transmit power & $50 \mathrm{~mW}$ \\
Modulation & FM-CW \\
Beamwidth & $2^{\circ}$ \\
Antenna & Offset parabola \\
Range resolution (adjustable) & $150,200 \mathrm{~m}$ \\
Number of range gates & 30 \\
Spectral velocity resolution & $0.191 \mathrm{~ms}^{-1}$ \\
Nyquist velocity range & $0-12.3 \mathrm{~ms}^{-1}$ \\
Integration time & $1 \mathrm{~min}$ \\
\hline
\end{tabular}

$\left(\mathrm{ms}^{-1}\right)$ and $Z(\mathrm{dBZ})$. The $N(D)$ is obtained from the following equation (Peters et al. 2005):

$$
N(D, z) \Delta D=\frac{\eta(D, z)}{\sigma(D)} \Delta D
$$

where $N(D, z)$ is the spectral drop number density at an altitude $z, \eta(D, z)\left(\mathrm{m}^{-1} \mathrm{~mm}^{-1}\right)$ is the spectral volume scattering cross section which is a function of drop diameter $D$. The term, $\sigma(D)\left(\mathrm{m}^{2}\right)$ is the single particle backscattering cross section of a raindrop diameter $D$. The radar reflectivity factor and rainfall intensity are $D^{6}$ and $D^{3.67}$ weighing of DSD, respectively. The electromagnetic energy is attenuated at $K$ band in moderate-tohigh rain. Rain attenuation correction is applied in the MRR data analysis software while deriving the rain parameters, following the recursive algorithm developed by Kunz (1998) described in Peters et al. (2005). Recently, Peters et al. (2010) developed a new algorithm to correct attenuation of electromagnetic wave due to rain. Aliasing of the reflectivity spectra in the presence of strong vertical wind during convective rain can result in faulty rain parameters, however, such phenomenon are less frequent in stratiform type of rain (Tridon et al. 2011). The vertical winds during stratiform rain rarely exceed $1 \mathrm{~ms}^{-1}$ (Cifelli and Rutledge 1994). To avoid any retrieval artifact of rain parameters, we restrict our study to low intensity rainfall events prevailed for long time. The data utilized in this study were collected during the two monsoon seasons of 2008 and 2009. Total 10 prolonged rain events that lasted for many hours are selected for this study which consists of nearly 2800 minutes of rainfall data.

The PARSIVEL is a laser based optical system; it detects rain particles ranging from 0.3 to $30 \mathrm{~mm}$. A $650 \mathrm{~nm}$ laser diode produces light sheet of $30 \mathrm{~mm}$ width and $180 \mathrm{~mm}$ long with output power of $3 \mathrm{~mW}$. The light is focused into a photo diode in the receiver end. In the absence of precipitation, it maintains a constant voltage while presence of precipitation causes decrease in output voltage. The decrease of the output voltage is proportional to the backscatter cross-section of the particle. The deviation of signal is a measure of particle size. Detailed discussion on PARSIVEL disdrometer can be found in Löffler-Mang and Joss (2000), Yuter et al. (2006), Nemeth and Löffler-Mang (2006).

\section{Results}

\subsection{Comparison of MRR observation with ground observations}

Figure 1 shows the scatter plot of every 5 minutes rain accumulation data between the collocated MRR and Automatic Weather Station (AWS). The AWS is located nearly $20 \mathrm{~m}$ away from the MRR. A correlation coefficient of 0.99 was found between them. Bias of $-4.24 \mathrm{~mm}$ revealed an underestimation rainfall measured by MRR with respect to AWS. It is to be noted that the AWS is a point measurement that uses a tipping bucket of resolution $0.5 \mathrm{~mm}$ while the MRR estimated $R$ is considered at the altitude of $450 \mathrm{~m}$ of an area $193 \mathrm{~m}^{2}$. The collecting area of the rain gauge is $0.01 \mathrm{~m}^{2}$. Good agreement is found between the rainfall measured by these two instruments despite their diverge physical and sampling characteristics. The mean DSDs during BB and NBB conditions at ground as obtained from PARSIVEL and MRR are shown in figure $2(\mathrm{a}, \mathrm{b})$. These two instruments are located nearly $100 \mathrm{~m}$ away from each other. The DSDs obtained from MRR were considered at the altitude of $450 \mathrm{~m}$ of an area $193 \mathrm{~m}^{2}$. The PARSIVEL's

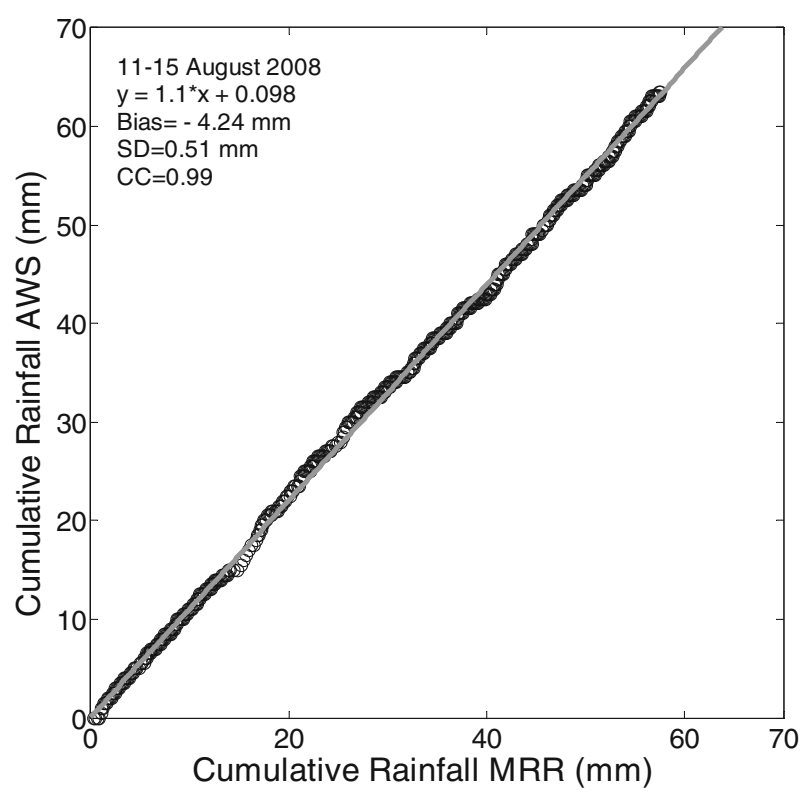

Figure 1. Scatter plot of cumulative $R$ measured by AWS and MRR for nearly $110 \mathrm{hrs}$. The rainfall intensity obtained from MRR are considered at $450 \mathrm{~m} \mathrm{AGL}$. 

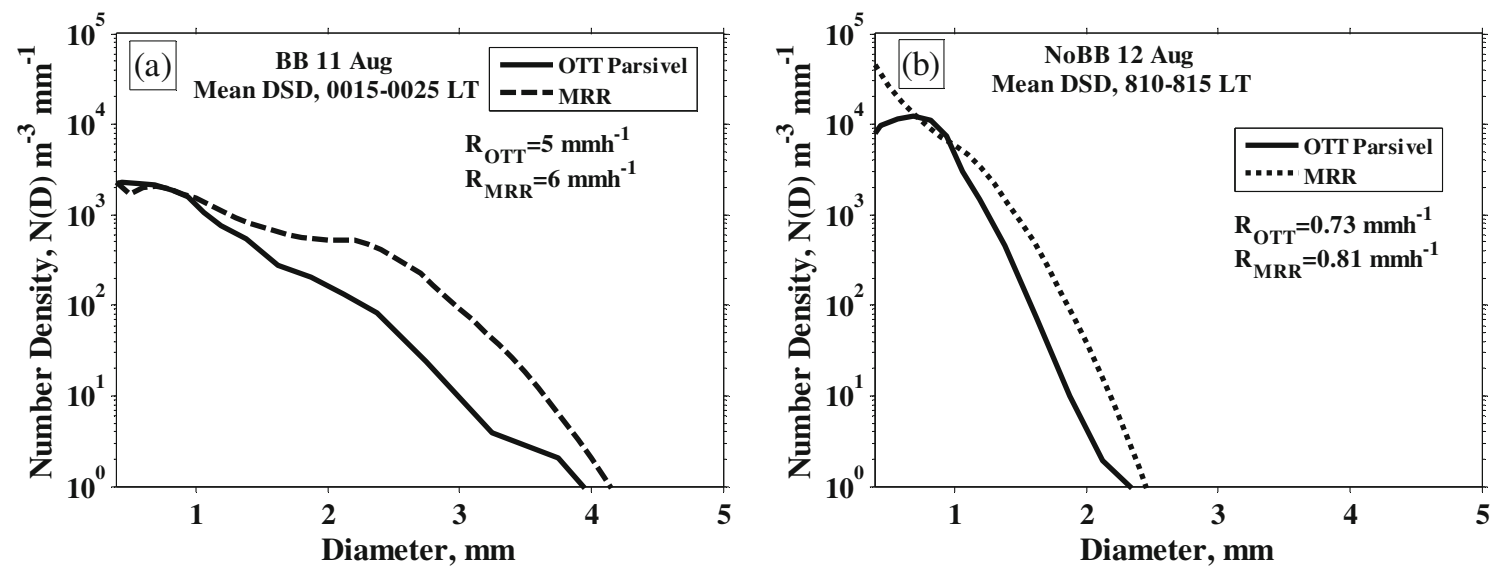

Figure 2. Rain DSDs at two instances during (a) BB on 11 August and, (b) no BB conditions on 12 August 2008. The MRR DSDs considered here were at $450 \mathrm{~m}$ AGL.

cross sectional area is $54 \mathrm{~cm}^{2}$. Bimodal DSD during $\mathrm{BB}$ and monomodal DSD during NBB conditions were observed both on ground and aloft.

\subsection{Rain drop size distributions in presence and absence of bright band}

Being situated on the leeward side of the Western Ghat, Pune is in the rain shadow region of India. Pune is situated $560 \mathrm{~m}$ above sea level on the Deccan plateau. It receives rain when large scale cyclonic circulation flow persists over this part of the subcontinent. In this section we studied the nature of light rain properties during the $\mathrm{BB}$ and NBB conditions with the help of a vertically pointing MRR. The height time intensity (HTI) plots of $Z, V$, gradient fall velocity (GFV) $\left(\mathrm{ms}^{-1} \mathrm{~km}^{-1}\right)$ of hydrometeors and temporal variations of $R$ are shown in figure $3(\mathrm{a}-\mathrm{h})$ for 11 August, 2008 and 20 August, 2009 during BB conditions, while for NBB conditions it is shown in figure $4(\mathrm{a}-\mathrm{h})$ for two events on 20 September, 2008 and 12 August, 2008, respectively. The HTI and temporal variation of the events are shown only for few hours for clarity. It is to be mentioned here that rainfall on 11 August was continued for nearly 19 hours with small gaps in between. The convective, BB and NBB spells of the events are marked in the panels. The BB condition is identified by the enhanced $Z$ near the $0^{\circ} \mathrm{C}$ isotherms and also by large GFV of hydrometeors. The storm heights of the events studied here are not resolved by the MRR as we operated it at the resolutions of 150 and $200 \mathrm{~m}$ that correspond to maximum ranges of 4.5 and $6 \mathrm{~km}$, respectively. Radar reflectivity of very small magnitudes could be seen above the melting layer during the BB conditions e.g., figure 3(e). Zawadzki et al. (2005) emphasized that the riming process between supercooled water and snow particles above the melting layer could result high density hydrometeors. The HTI plot of hydrometeor fall velocity $V\left(\mathrm{~ms}^{-1}\right)$ is shown in figure $3(\mathrm{~b}, \mathrm{f})$. The fall velocity of the hydrometeors, $V$ is increased below the $0^{\circ} \mathrm{C}$ isotherm which revealed the presence of liquid phase of hydrometeors. Large hydrometeors are formed when ice particles grow by vapour deposition, aggregation and rimed to become large snowflakes which finally melt to form large raindrops. The little significant fall velocity of hydrometeors above the melting layer might suggest the presence of snow hydrometeors. The GFV is found to be a good indicator of the melting layer when enhanced $Z$ is not prominent. This can be seen in the figure $3(\mathrm{c}, \mathrm{g})$, where prominent GFV contours are well marked at some instant of the storm even though signature of BB are faint. The contour plots of GFV indicate the altitudes where melting layers are centered and extended. It is very interesting to note the core of maximum GFV at the melting layer, above and below of which GFV decreases. Maximum GFV of the order $20 \mathrm{~ms}^{-1} \mathrm{~km}^{-1}$ is observed which indicates rapid change of hydrometeor velocities within the melting layer. This may be due to the formation of large liquid hydrometeors in the melting layer in expense of snow particles of lesser velocity where conversions from snow to liquid phase hydrometeors take place. The finding that GFV decreases above and below the melting layer was reported earlier by Lhermitte and Atlas (1963).

The storm height during NBB conditions are below the $0^{\circ} \mathrm{C}$ isotherm as revealed from figure 4 . The $0^{\circ} \mathrm{C}$ isotherm is located at nearly $4.2 \mathrm{~km}$ on 12 August and $4.6 \mathrm{~km}$ on 20 September 2009 as obtained from the Mumbai radiosonde observations. No well defined BB and contours for GFV exist in the shallow precipitating system. Significant radar echoes for NBB events are observed from 2 to $3 \mathrm{~km}$ which seems to be resolved by the 

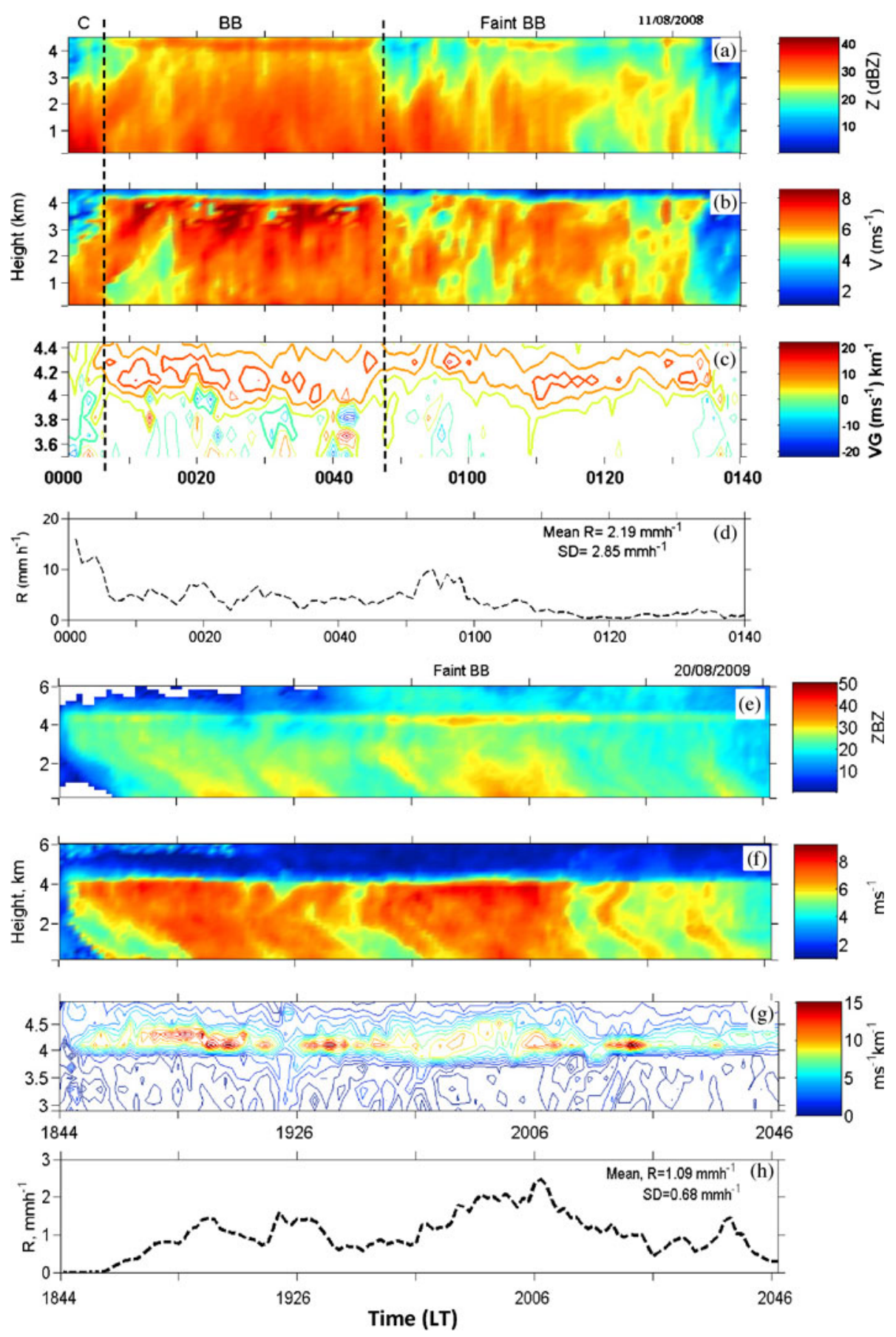

Figure 3. HTI plot of Radar Reflectivity Factor $Z$ in dBZ (a, e), Fall velocity V (b, f), contour plot of Gradient Fall Velocity in the melting layer (c, g) and temporal variation of $R$ at $\sim 450-600 \mathrm{~m}$ height $(\mathbf{d}, \mathbf{h})$ for 11 August, 2008 and 20 August, 2009, respectively. The convective spell is indicated by $\mathrm{C}$ while bright band spells by $\mathrm{BB}$. Enhanced $Z$ is observed at around $4.2 \mathrm{~km}$ at which the melting layer is located.

MRR. This means that the raindrops as observed by the MRR during NBB conditions are formed at much warmer temperature than the $\mathrm{BB}$ conditions. The shallow precipitating systems are characterized by low intermittent rainfall (e.g., figure 4d, h). Steady rainfall occurred with deviations smaller from the mean values are shown in the panels.

Does the MRR able to resolve the heights of the storms under study? To answer this question, we used two satellite passes near to Pune. Figure 5 illustrates the storm structure as seen by the onboard Cloud Profiling Radar (CPR) at $94 \mathrm{GHz}$ in the CloudSat (Stephens et al. 2002) satellite on 11 August and 12 August 2008. CPR provides storm information in terms of equivalent radar reflectivity factor $\left(\mathrm{dBZ}_{\mathrm{e}}\right)$. Enhanced $\mathrm{dBZ}_{\mathrm{e}}$ could be observed above $4 \mathrm{~km}$ which suggests presence of $\mathrm{BB}$ on 11 August. Evidence of stratiform cloud formed 

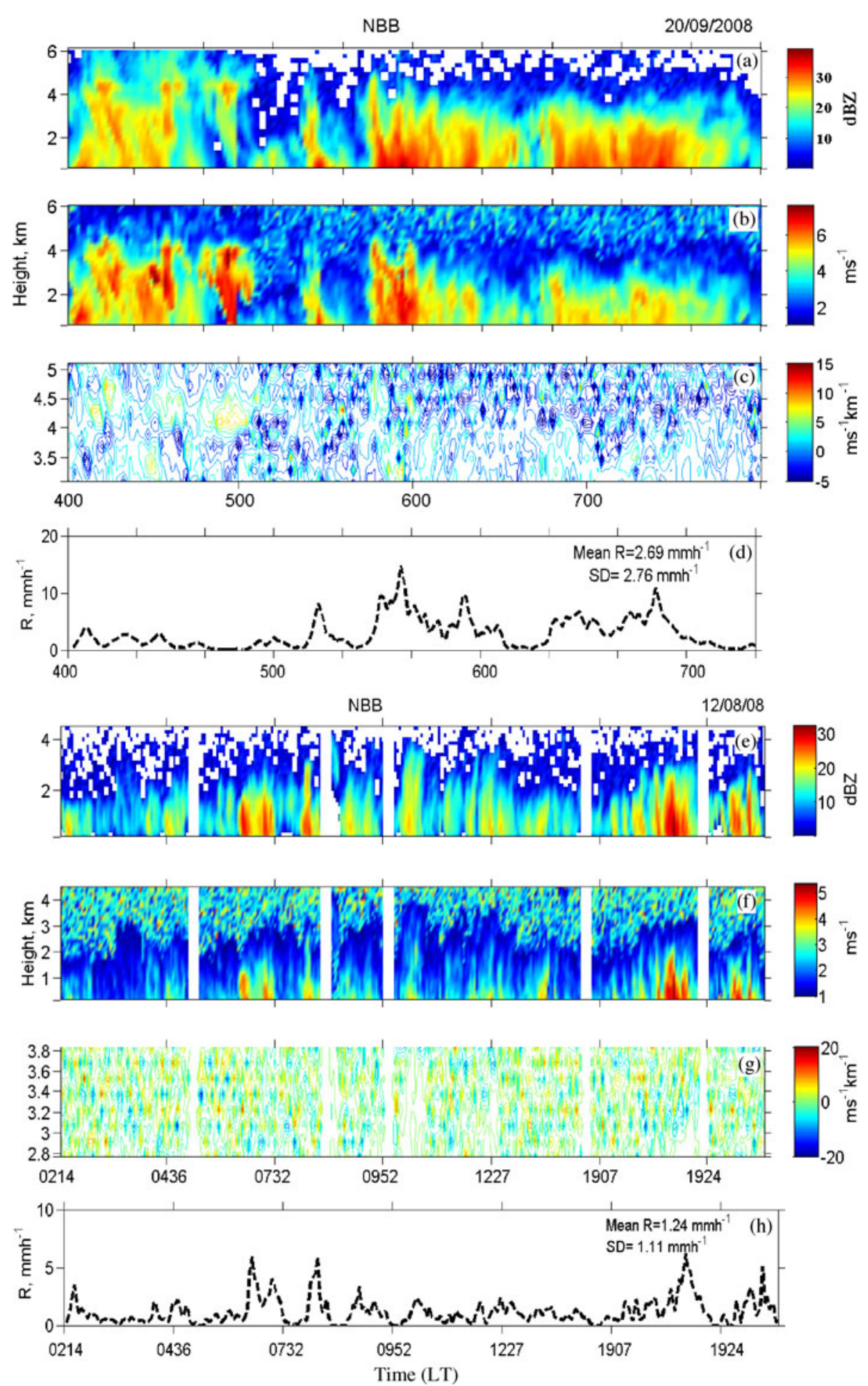

Figure 4. Same as figure 3 but for 20 September, and 12 August 2008 during no Bright Band (NBB) conditions. The $0^{\circ} \mathrm{C}$ isotherm is located at $\sim 4.2 \mathrm{~km}$ on 12 August and $\sim 4.6 \mathrm{~km}$ on 20 September 2009 as obtained from Mumbai sounding.

by cooled microphysical processes can be inferred from figure 5(a). Very weak reflectivity of the order $-30 \mathrm{dBZ}_{\mathrm{e}}$ at temperature $\sim-60^{\circ} \mathrm{C}(15 \mathrm{~km})$ suggests presence of ice particles. This reconfirms that the cold microphysical processes are responsible for stratiform rain over the tropics. The storm structure on 12 August 2008 as captured by the
CloudSat satellite revealed that the precipitating system was composite of multiple shallow cells with storm heights not exceeding 4 to $5 \mathrm{~km}$ (in most cases) that covers area greater than $300 \mathrm{~km}^{2}$. The shallow storm height on 12 August clearly depicts warm rain process. High altitude cirrus clouds at $10 \mathrm{~km}$ are also noticed. Very significantly, these 

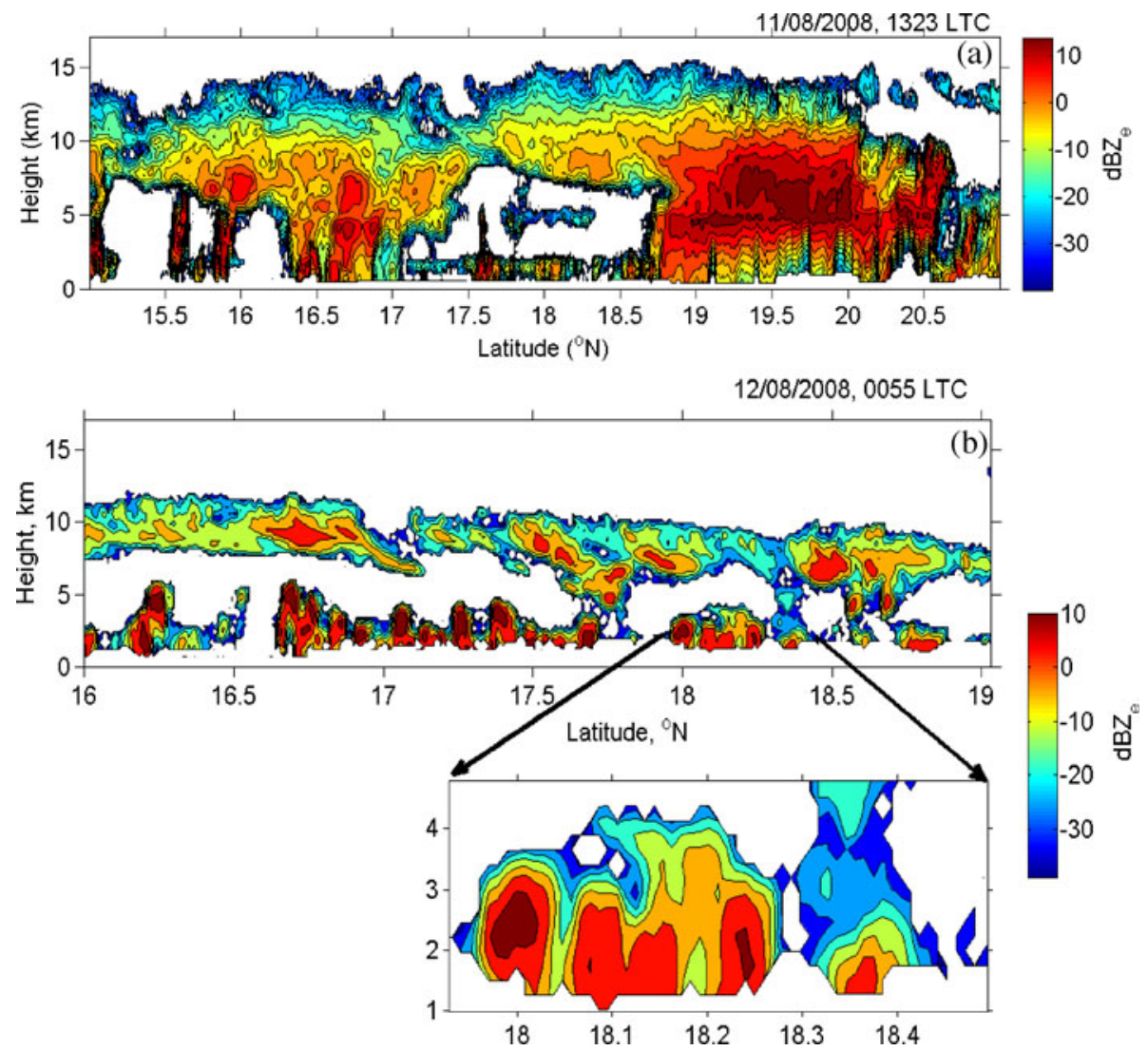

Figure 5. (a, b) Storm structure as seen by CloudSat satellite (a) on 11 August 2008 at 1323 LT. Stratiform with enhanced equivalent radar reflectivity factor $\mathrm{dBZ}_{\mathrm{e}}$ around $4-5 \mathrm{~km}$ suggest presence of bright band. (b) On 12 August 2008 at 0055 LT. High altitude cirrus cloud is observed at $10 \mathrm{~km}$. The storm near to Pune is enlarged and shown as arrowed inset. The storm is composite of shallow cells not exceeding $4 \mathrm{~km}$ identical to precipitating system as observed by MRR shown in figure $4(\mathrm{e})$.
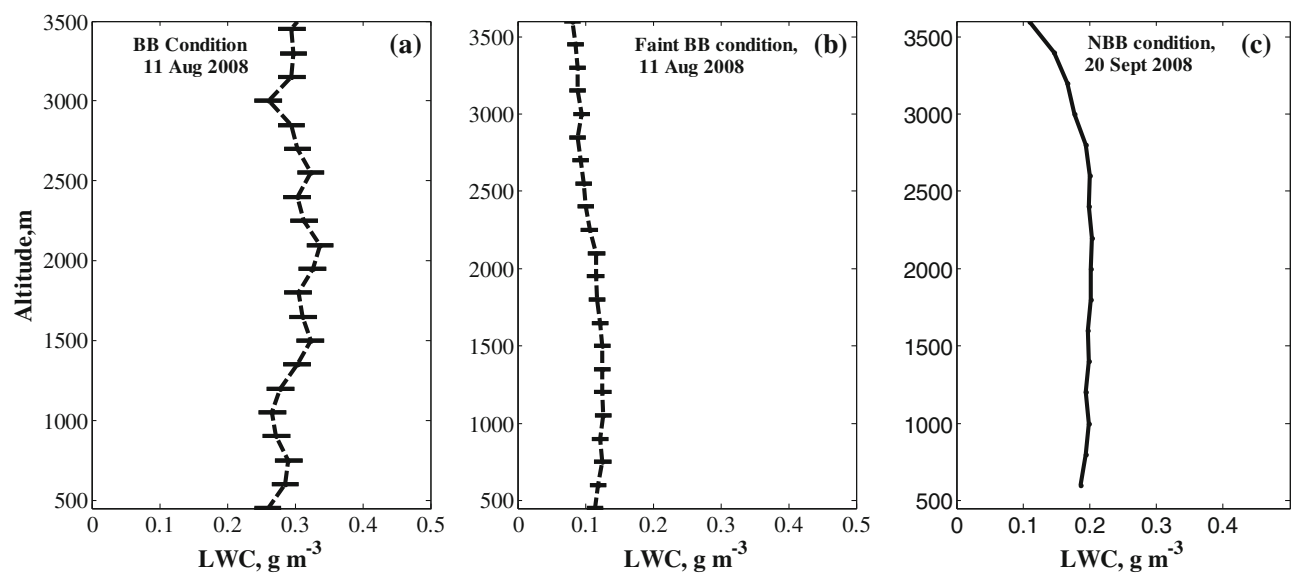

Figure 6. Mean LWC profile during (a) BB (from 0010 to 0035 LT) and (b) faint BB (0502 to 0700 LT) and (c) NBB on 11 August 2008 and 20 September, 2008, respectively. The mean rainfall intensity during BB condition was 4.61 mmh ${ }^{-1}$,

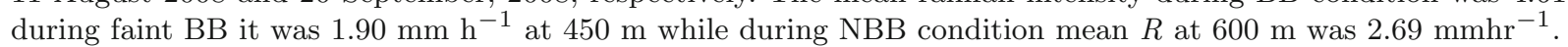

cirrus clouds seem to merge with the pocket of shallow cells latitudewise. The dynamical cause for this mechanism is a scope for further study. The precipitating system near to Pune region is enlarged and shown in figure 5(b). It can be seen that the storm height was below $4 \mathrm{~km}$ with significant $\mathrm{dBZ}_{\mathrm{e}}>0$. A storm is classified as deep convective clouds when the cloud top penetrates $0^{\circ} \mathrm{C}$ isotherm level accompanied by heavy rainfall and vigorous updraft (Williams et al. 1995; 

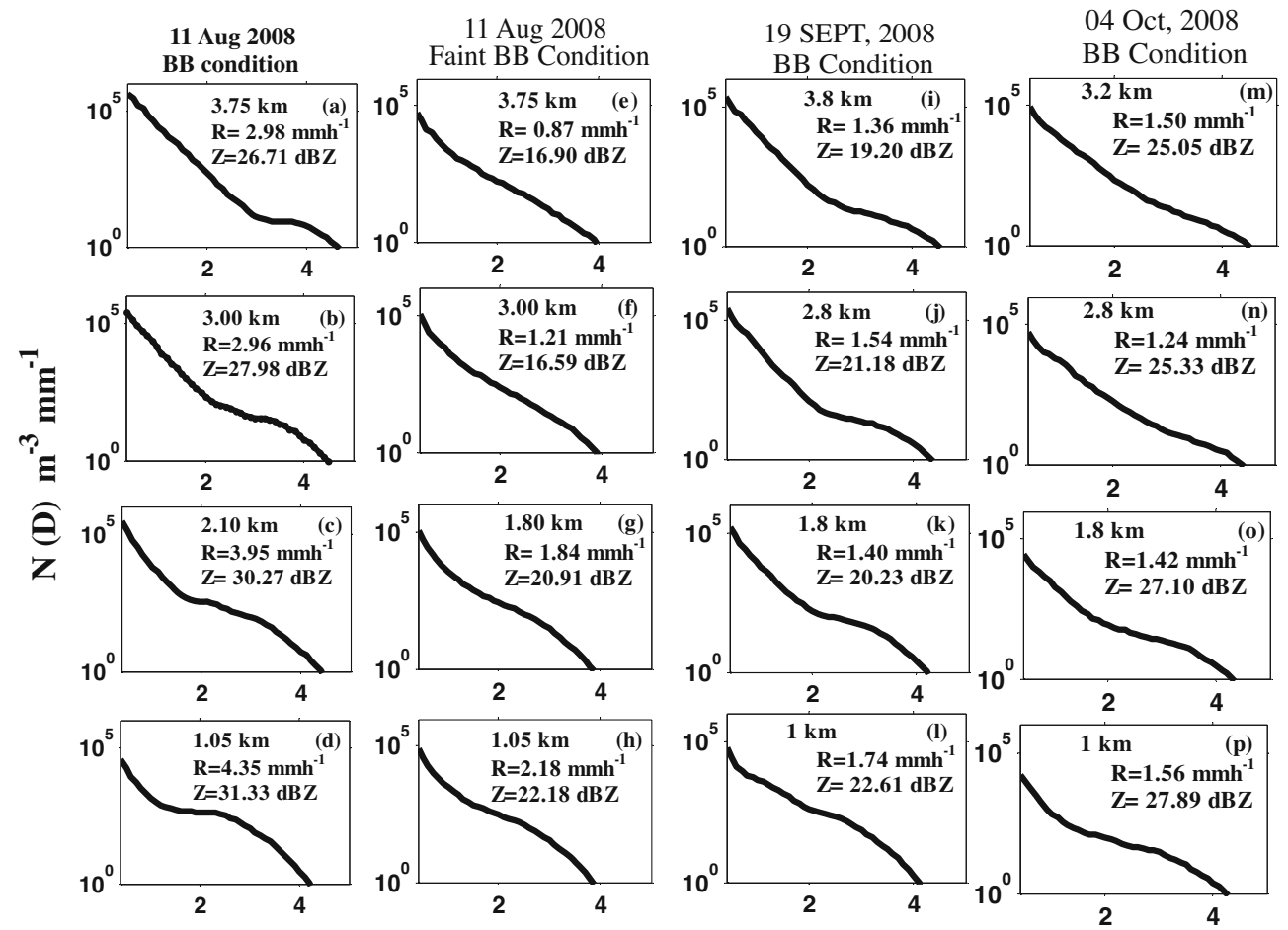

Diameter, $\mathbf{m m}$

Figure 7. (a-p). Evolution of mean DSDs as they fall from nearly $4 \mathrm{~km}$ to $1 \mathrm{~km}$ for BB and faint BB conditions as observed from MRR for different events stated on the panels. The profiles are the mean DSDs for BB or faint BB period at different altitudes. Bimodal DSDs could be observed that become more prominent at the mid-rain drop diameters (2-4 mm). The mean value of $R$ and $Z$ are shown on each panel at different altitudes.

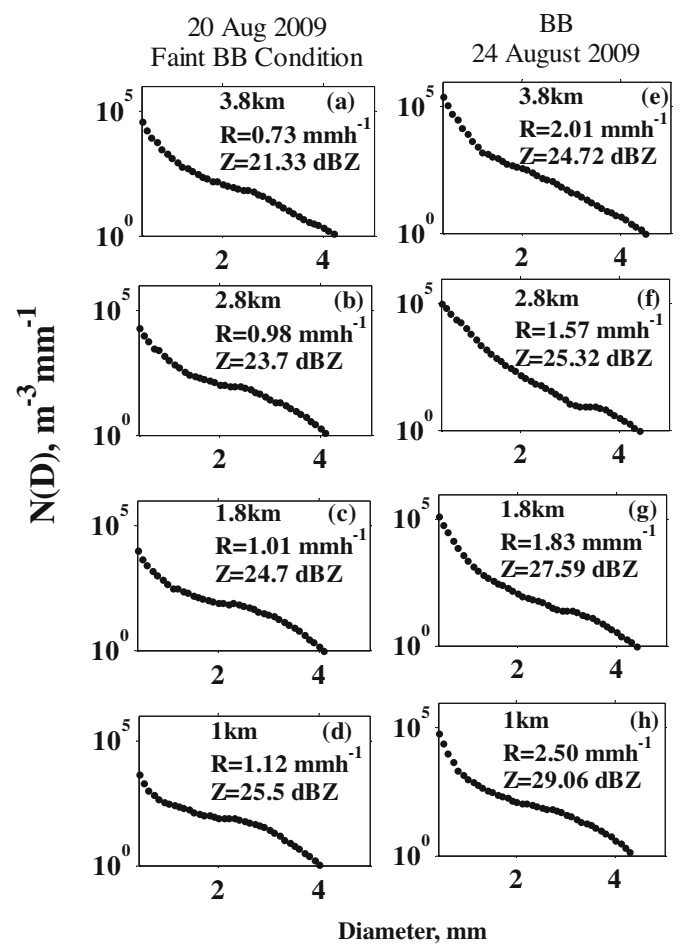

Figure 8. Same as figure 7 but for 20 and 24 August 2009.
Rao et al. 2001; Sharma et al. 2009). Since the storm heights are at warm temperatures and persist for a long duration, it may be suggested that these NBB clouds are originated from orographically and synoptically forced shallow convective cloud cells. Since these NBB storm heights are below $0^{\circ} \mathrm{C}$ isotherm level and characterized by low rainfall intensity, we categorize them as nonconvective clouds. The CPR observations also suggest that the MRR could able to resolve the storm structures that may produce light rain.

It is important to know if rain liquid water content (LWC) $\mathrm{gm}^{-3}$ conserve at different altitudes as observed by the MRR. The profile of rain LWC is shown in figure $6(\mathrm{a}, \mathrm{b}, \mathrm{c})$ which suggests that the observed LWC during $\mathrm{BB}$ is more than the faint $\mathrm{BB}$ conditions. The LWC at $0.45 \mathrm{~km}$ during $\mathrm{BB}$ is $0.26 \mathrm{~g} \mathrm{~m}^{-3}$ while at $3.5 \mathrm{~km}$ it is $0.32 \mathrm{~g} \mathrm{~m}^{-3}$, implying a decrease by nearly $18 \%$ (e.g., figure $6 \mathrm{a}$ ). The LWC for faint $\mathrm{BB}$ condition at $3.6 \mathrm{~km}$ is nearly $0.09 \mathrm{~g} \mathrm{~m}^{-3}$ while at $0.45 \mathrm{~km}$ it is $0.10 \mathrm{~g} \mathrm{~m}^{-3}$. Hence there is a change of $10 \%$ of LWC between these two heights (figure 6b). For an NBB condition, the mean LWC profile is shown in figure 6(c). As the precipitating system was shallow, LWC of $0.2 \mathrm{~g} \mathrm{~m}^{-3}$ could be observed from below $3.0 \mathrm{~km}$ decreasing to a value of $0.19 \mathrm{gm}^{-3}$ at $0.6 \mathrm{~km}$. Mean 

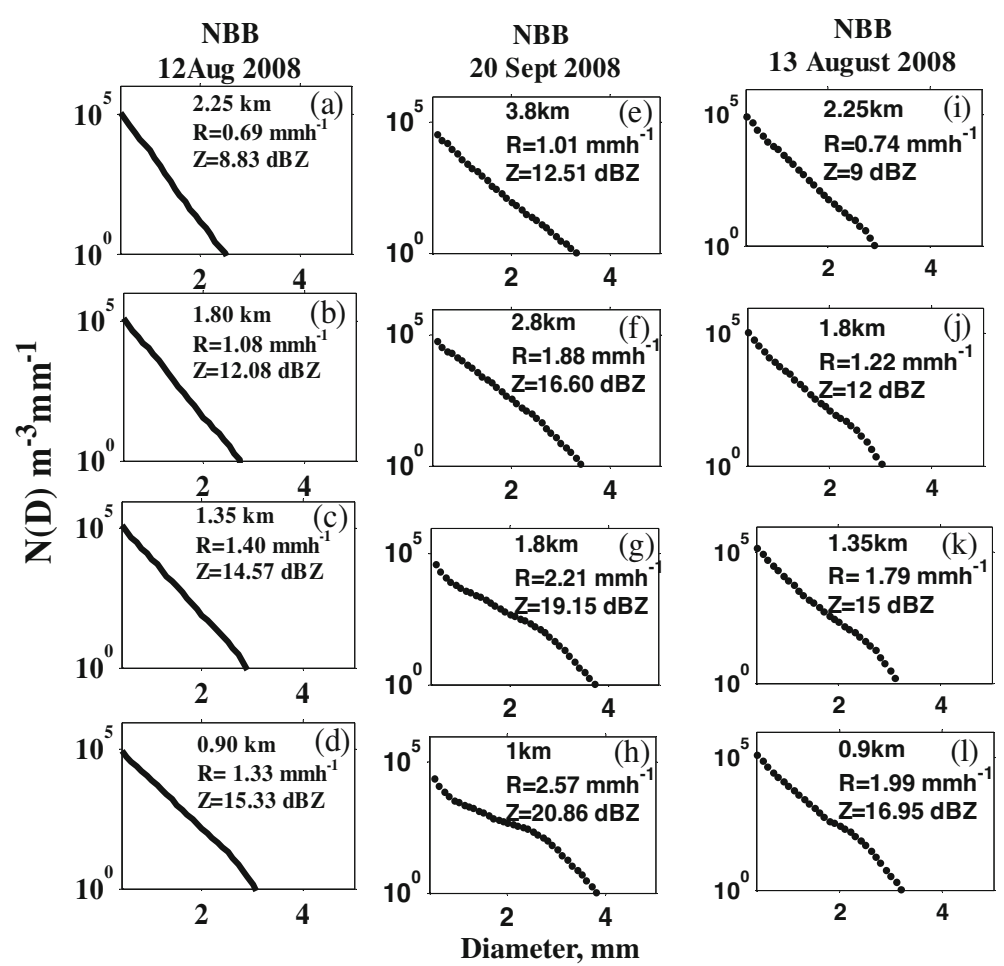

Figure 9. Same as figure 7 but for NBB conditions. The NBB conditions were of shallow precipitating systems; the $R$ and $Z$ were of small values at the higher altitudes. The DSD shapes are nearly monomodal at the higher altitudes with insignificant secondary modes.

LWC for the BB and NBB are nearly equal while mean LWC during faint BB conditions are smaller. Smaller difference of LWC for BB and NBB conditions is reported by Martner et al. (2008), they suggested that the DSDs are similar across the mid drop size range but different at smaller and large drop diameters. The near conservation of LWC at higher and lower altitudes may also indicate that attenuation does not affect severely during low intensity rainfall.

Figures 7 and 8 show mean DSD from $\sim 1.0$ to $3.8 \mathrm{~km}$ during $\mathrm{BB}$ and faint $\mathrm{BB}$ conditions. We define here ranges of drop diameters: $D$ less than $2 \mathrm{~mm}$ was defined as small, $2-4 \mathrm{~mm}$ as middle, and greater than $4 \mathrm{~mm}$ as large. During the faint $\mathrm{BB}$ and well defined $\mathrm{BB}$ conditions, bimodal DSD is observed. The bimodal shapes are more prominent in presence of BB. The bimodal DSD is composed of uniform shape of small to mid $D$ and tail extending from mid to large $D$. The large raindrops present in the spectrum may be attributed to the aggregation process in the melting layer. Figure $9(\mathrm{a}-\mathrm{l})$ shows the profile of DSDs during NBB conditions. In contrast to the bimodal DSD during BB condition, monomodal DSDs are observed at the higher altitude during NBB conditions. However given enough time to fall, it becomes bimodal at lower altitudes, e.g., figure $9(\mathrm{e}-\mathrm{h})$. We do not have more observation of such cases, however coalescence process could be a physical process taken place that result such bimodal shapes at lower altitudes. A significant observation in DSDs during NBB was greater number density along the small range drop diameters at all altitudes than the BB conditions. For shallow precipitating systems $(\sim 2-3 \mathrm{~km})$, monomodal DSDs were found at all altitudes, e.g., figure $9(\mathrm{a}-\mathrm{d}$ and $\mathrm{k}-\mathrm{l}$ ). Slight increment in the mean $R$ and $Z$ values could be observed from upper to lower altitudes illustrated on the panels of each figure (7$9)$. With respect to low rainfall intensity, Peters et al. (2005) reported negative gradient of $R$ from $800 \mathrm{~m}$ above, they attributed it to the cloud top. They also reported negative gradient of $Z$ values for all rainfall class which is attributed to the shift of DSDs towards low diameter range.

\subsection{Normalized DSDs at different altitudes}

The normalized DSDs obtained from a ground based disdrometer follow intrinsic shape for both high (convective) and low (stratiform) intensity rain (Testud et al. 2001; Konwar et al. 2006) as stated earlier. We present here the normalized DSDs at different altitudes for low intensity rain in the presence and absence of BB. Figure 10 shows the normalized DSD at different altitudes for both the cases. The mean DSDs at different altitudes 

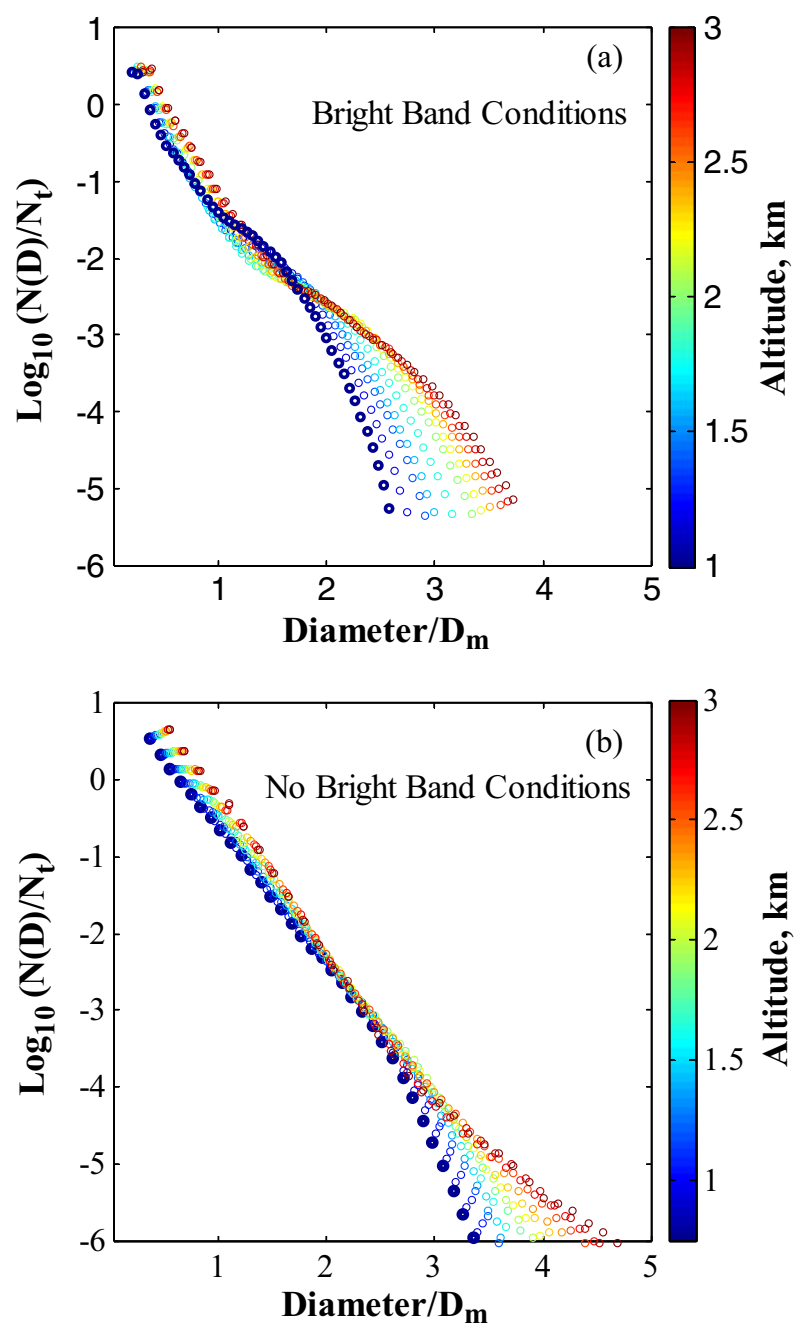

Figure 10. Normalized DSDs (a) in presence of bright band and (b) in absence of bright band, at different altitudes as the rain drops fall from higher to lower altitudes (indicated by the colour bar) as observed from MRR. The DSDs are scaled by the total number concentration, $N_{t}$ and the diameter is scaled by mean volume diameter, $D_{\mathrm{m}}(\mathrm{mm})$.

are normalized by the number concentrations and plotted against $D / D_{\mathrm{m}}$. The term $D_{\mathrm{m}}(\mathrm{mm})$ is the mean volume diameter defined as the ratio of $4 \mathrm{th}$ to 3rd moment of the DSD spectra; physically it partitions the DSDs into two equal parts of same LWC. During BB conditions, the normalized DSDs we obtained here are similar to universal shape normalized DSDs obtained by Testud et al. (2001). Significantly however, in case of NBB conditions, the normalized DSDs are monomodal at all altitudes shown in figure 10(b). It is also interesting to note the significant decrease in the scaling factor $D / D_{\mathrm{m}}$ as the raindrops reach the ground (see figure 10b). This means there exist distinct dominant microphysical processes responsible for different normalized DSD shapes during BB and NBB conditions, respectively. An effort has been made in the following section to find the microphysical processes responsible for different shapes of DSDs.

\subsection{Plausible microphysical processes for bimodal and monomodal DSD}

Steiner et al. (2004) suggested that DSD shapes is governed by

- variation in the $N(D)$

- variation in the drop sizes and

- by coordinated mixed variation of $N(D)$ and drop sizes.

Based on these assumptions, we suggest plausible microphysical processes responsible for the bimodal and monomodal DSDs. For this, fraction of $N(D)$, i.e., $N(D)_{\text {Test }} / N(D)_{\text {Reference }}$ at different altitudes with respect to $\sim 1.00 \mathrm{~km}$ utilized is shown in figures 11, 12 and 13. Figures 11 and 12 illustrate the change in number densities for faint $\mathrm{BB}$ and $\mathrm{BB}$ conditions while figure 13 represents the same for NBB conditions. For the BB and faint BB conditions, increment in $N(D)$ of the midrange drops falling from higher to lower altitude are noticed, evident from $N(D)_{\text {Test }} / N(D)_{\text {Reference }}<1$ for the mid-range drops. The relative increase of $N(D)$ in the mid-range could be attributed to the breakup of large raindrops at higher altitudes and also to the coalescence process among the smaller drops at lower altitudes. The breakup of large drop diameters suggested number controlled processes. For large and small drop size ranges, we found $N(D)_{3.75 \mathrm{~km}} / N(D)_{1.00 \mathrm{~km}}>1$, which revealed decrement in small and large drop diameter $N(D)$. It could be visualized that all the large drop diameters do not survive and some of them break up before reaching the ground while some of the small drop diameters could coalesce to form midrange drops. The small range raindrops might also evaporate faster due to the curvature effect. Slight increase of $Z$ in the lower altitudes could be attributed to the contributions from the mid-range drop diameters (see figures 7 and 8). Absence of strong updrafts during stratiform rain inhibits formation of large raindrop in the mid-altitudes. This is realized from the observed $N(D)$ spectrum at lower altitudes where the contributions from large drops are less. The large drop diameters present during $\mathrm{BB}$ conditions are primarily governed by the width of the $\mathrm{BB}$, i.e., larger the width of the $\mathrm{BB}$, the larger the drop diameter (Sharma et al. 2009). In presence of $\mathrm{BB}$, the DSDs are characterized by the peak at mid-range raindrops which results in bimodal DSDs at the lower altitudes. It is suggested that collision, coalescence and breakup are the primary microphysical processes responsible for the bimodal DSDs. 

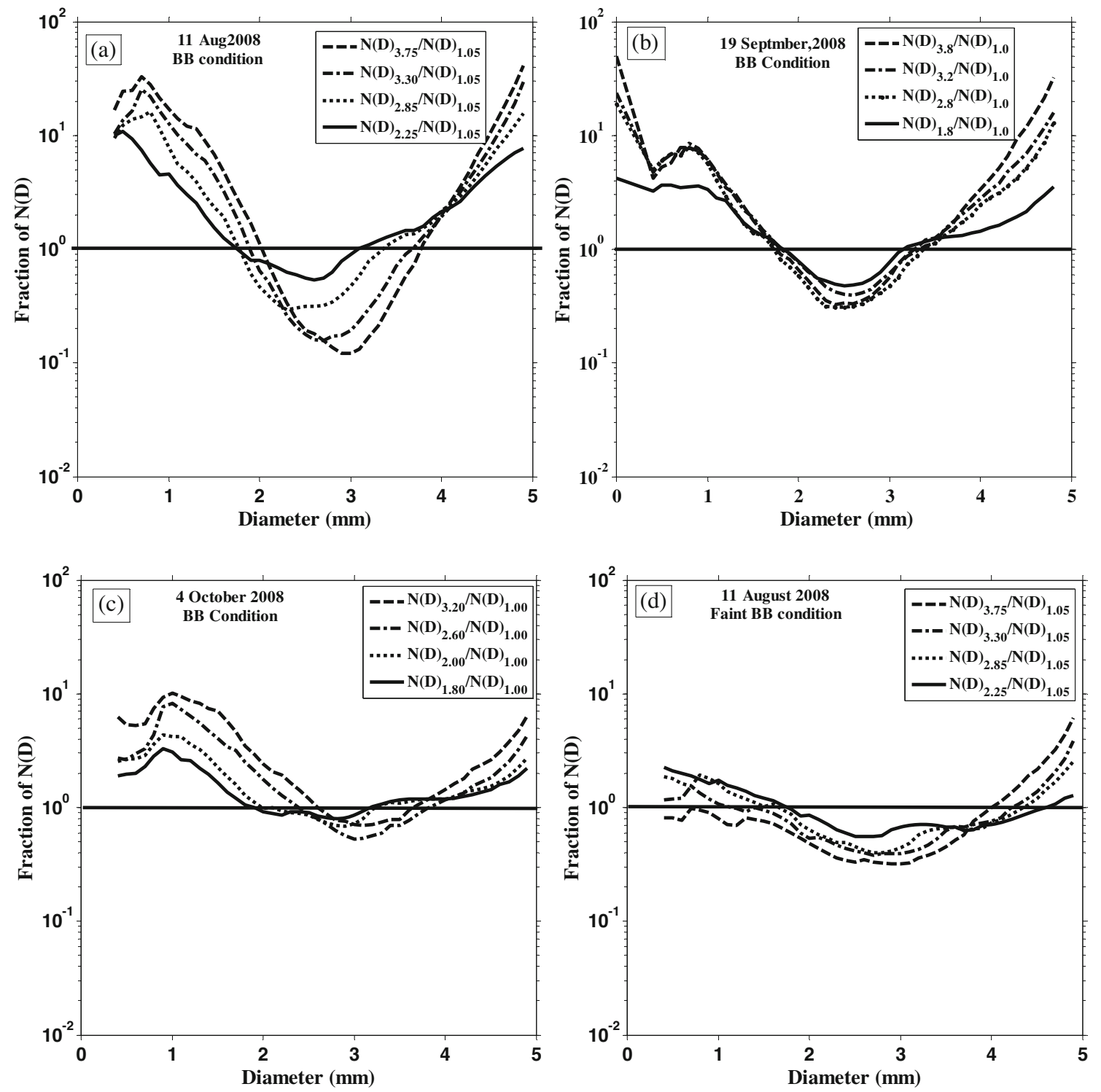

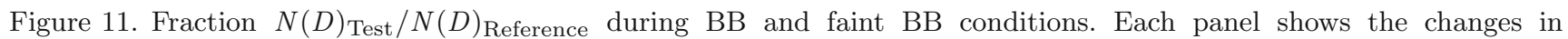
rain DSDs for different events at higher altitudes with respect to the reference altitude at nearly $1 \mathrm{~km}$. Increase $\left(N(D)_{\text {Test }} / N(D)_{\text {Reference }}<1\right)$ or decrease $\left(N(D)_{\text {Test }} / N(D)_{\text {Reference }}>1\right)$ in DSDs at the referenced altitude $\sim 1 \mathrm{~km}$ with respect to DSDs at higher altitude can be seen at different diameter ranges such as small $(D<2 \mathrm{~mm})$, mid range $(2<$ $D<4 \mathrm{~mm})$ and large $(D>4 \mathrm{~mm})$.

For NBB conditions, the criteria, i.e., $N(D)_{3.75 \mathrm{~km}} / N(D)_{1.00 \mathrm{~km}}<1$ is found from mid to large diameter, which demonstrated increment in number density of large drops at lower altitude (see figure 13). Though we found increment in $N(D)$ towards the large drop diameter during NBB conditions, the growth in $N(D)$ at large drop diameter ranges are not that significant for an obvious prominent bimodal DSD. However, it may be noted that given the raindrops fallen from much higher altitude the mid-range raindrops may increase (e.g., figure 13c). The increase in $D_{\mathrm{m}}$ evident from figure 10 (b) also revealed that the number density at large drop diameters increases which suggested collision and coalescence among the small and mid-range drop diameters. As it is mentioned earlier, for the shallow NBB precipitating systems, significant $Z$ values are being observed below 2-3 km. Rogers et al. (1991) showed that during light rain, raindrops grow by accretion, they neither created by autoconversion nor destroyed by breakup processes.

\subsection{Variation of $Z-R$ relationships during $B B$ and $N B B$ conditions}

The microphysical properties of the precipitating systems could be studied with the help of $Z-R$ relationships (Steiner et al. 2004). We examined here whether the number/size controlled process during 

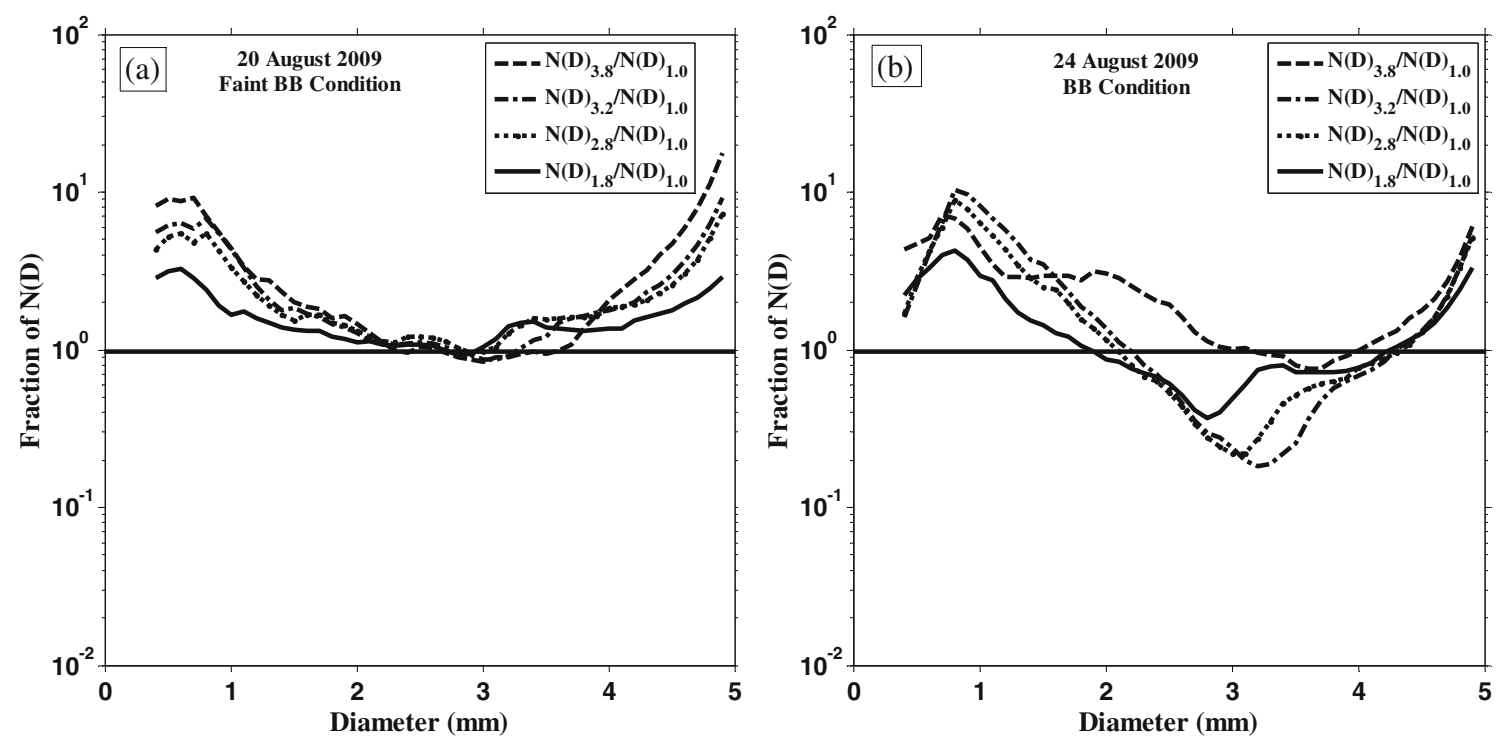

Figure 12. Same as figure 9 but for (a) 20 August 2009 during faint BB conditions and (b) 24 August, 2009 during BB conditions.

$\mathrm{BB}$ and faint $\mathrm{BB}$ conditions, and size controlled process during NBB conditions are represented by the coefficient and exponent of $Z-R$ relationships. We listed the values of coefficient and exponent of $Z-R$ relationships reported from different places of the globe during stratiform rain (see table 2). Here, for each event, we found out the coefficient and exponent of $Z-R$ relationships for the $\mathrm{BB}$ and NBB conditions at $3 \mathrm{rd}$ range height bin. The coefficient and exponents are presented in table 3 . Interestingly two distinct scenarios are evolved from these two tables: first, large coefficient with small exponent and second, small coefficient with large exponent. We found that in most of the cases, the exponents are ranged from 1.01 to 1.25 during the $\mathrm{BB}$ condition (see table 3 ). It could be attributed to the coalescence and collisional breakup process, i.e., number and size controlled processes. Exponent of near unity during stratiform rain is reported by earlier studies, e.g., Atlas et al. (1999), Maki et al. (2001), Sharma et al. (2009). The coefficients are large during BB condition which signifies presence of large raindrops. During faint BB conditions, we found slightly large exponent values which might suggest more size controlled process than distinct $\mathrm{BB}$ conditions. Rogers et al. (1991) reported large exponent values of $Z-R$ relationships during stratiform like rains with $R<1 \mathrm{mmh}^{-1}$ and $Z<20 \mathrm{dBZ}$ originated from orographic warm based cloud systems. During NBB conditions the exponents are large with smaller coefficient. The small coefficient could be attributed to the presence of large number density in the small drop diameter range. This could be due to less aggregation process in absence of $\mathrm{BB}$ which inhibits formation of very large raindrops aloft.
The large exponent values during NBB conditions could be attributed to the collision and coalescence processes among the small to mid-drop diameters. This is illustrated in figure 9 for NBB conditions where the DSD shape extended to large drop diameter range. It could be that the exponent tends to be unity from $\mathrm{NBB}$ to faint $\mathrm{BB}$ and then to $\mathrm{BB}$ conditions. This difference has become more prominent when the $\mathrm{BB}$ is well defined.

\section{Discussions}

The microphysical properties of stratiform rain are studied as measured by MRR over a tropical station at Pune, India. The vertical evolution of DSDs and microphysical properties are studied during faint $\mathrm{BB}, \mathrm{BB}$ and $\mathrm{NBB}$ conditions. The presence of $\mathrm{BB}$ is identified by the strong gradient of hydrometeor fall velocity and enhanced radar reflectivity factor in the vicinity of the melting layer (Williams et al. 1995; Houze 1997; White et al. 2002; Martner et al. 2008; Sharma et al. 2009). Rain microphysical processes are studied with the help of number density. The results of this study are summarized as follows:

- Variations of DSDs are confirmed by MRR and disdrometer at ground and aloft. Bimodal and monomodal DSDs are found both aloft and at ground in presence and absence of BB, respectively.

- Observation from CPR aboard CloudSat suggests evidence of existence of ice hydrometeors at temperature down to $-60^{\circ} \mathrm{C}$ during stratiform precipitation. Enhanced equivalent radar 

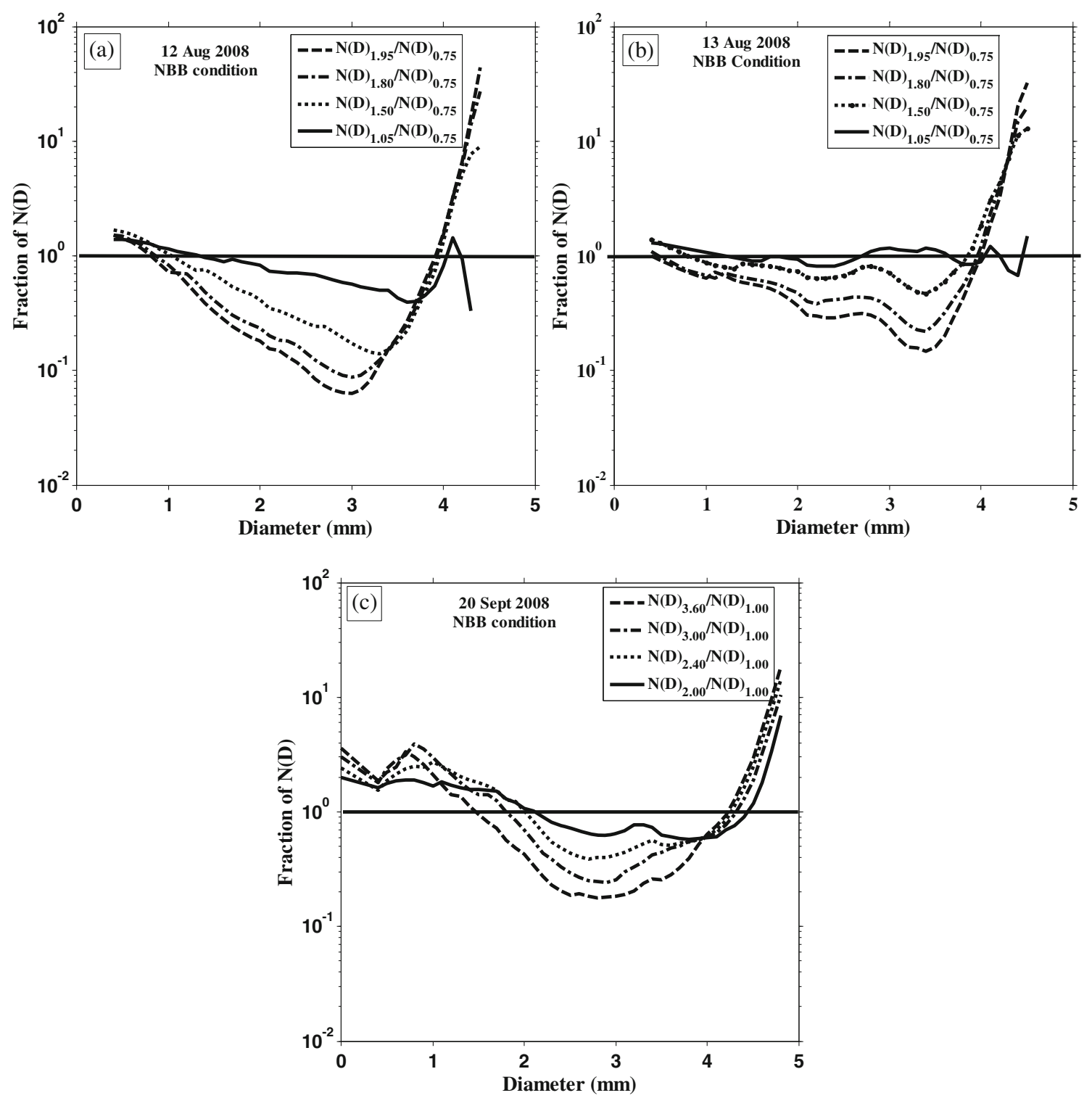

Figure 13. Same as figure 10 but for 12, 13 August 2008 and 20 September 2008 during NBB conditions.

reflectivity factor near to $4 \mathrm{~km}$ confirmed the presence of $\mathrm{BB}$ on 11 August. On the other hand, shallow precipitating systems with cloud tops warmer than $0^{\circ} \mathrm{C}$ are found during $\mathrm{NBB}$ conditions on 12 August 2008. This means that primarily warm cloud microphysical processes are responsible for producing rainfall from such shallow clouds.

- Light rain in the presence and absence of bright band signature are reported over the tropical station Pune, India. Observation of nonconvective rain without $\mathrm{BB}$ is in line with the finding of Martner et al. (2008); they reported such events of low rainfall intensity over Cazadero, and California flat valley in the USA.

- During BB and faint BB conditions, bimodal DSDs are observed which is attributed to the number and size controlled processes. Compli- mentary to the earlier finding large raindrops are found in presence of $\mathrm{BB}$ which is attributed to the size controlled process due to vapour diffusion and aggregation of snowflakes (Steiner et al. 2004). The breakup of large raindrops and coalescence of smaller drops could lead to the bimodal shape at the lower altitudes. Shallow precipitating system with low rainfall intensity is characterized by monomodal DSD at all altitudes. The small to mid-range raindrops collide to form large raindrops while reaching the ground.

- Different rain microphysical processes during $\mathrm{BB}$ and NBB conditions are confirmed by the normalized DSD. The normalized DSD during $\mathrm{BB}$ conditions are characterized by prominent bimodal shape while during NBB conditions shapes of normalized DSDs are monomodal. 
Table 2. Coefficients and exponents of $Z=a R^{b}$ relationships during stratiform rain.

\begin{tabular}{|c|c|c|}
\hline \multirow[b]{2}{*}{ Reference } & \multicolumn{2}{|c|}{ Stratiform rain } \\
\hline & Coefficient ' $a$ ' & Exponent ' $b$ ' \\
\hline \multirow[t]{5}{*}{ Sharma et al. (2009) } & 733 & 1.14 \\
\hline & 562 & 0.97 \\
\hline & 490 & 1.24 \\
\hline & 604 & 1.38 \\
\hline & 467 & 1.17 \\
\hline \multirow[t]{2}{*}{ Martner et al. (2008) } & 168 & 1.58 \\
\hline & 44 & 1.91 \\
\hline Ulbrich and Atlas (2007) & 280 & 1.46 \\
\hline Maki et al. (2001) & 532 & 1.28 \\
\hline Rao et al. (2001) & 251 & 1.51 \\
\hline Rao et al. (1999) & 447 & 1.38 \\
\hline \multirow[t]{6}{*}{ Atlas et al. (1999) } & 233 & 1.01 \\
\hline & 252 & 1.61 \\
\hline & 89 & 1.90 \\
\hline & 279 & 1.48 \\
\hline & 278 & 1.44 \\
\hline & 865 & 1.08 \\
\hline
\end{tabular}

Table 3. Coefficients and exponents of $Z-R$ relationships during bright band $(B B)$ and faint $B B$ and no bright band $(N B B)$ conditions.

\begin{tabular}{llcc}
\hline Date & Condition & Coefficient & Exponent \\
\hline 11 August 2008 & BB & 295 & 1.01 \\
-do- & Faint BB & 130 & 1.17 \\
12 August 2008 & NBB & 40 & 1.55 \\
13 August 2008 & NBB & 40 & 1.62 \\
19 September 2008 & BB & 222 & 1.16 \\
-do- & NBB & 88 & 1.56 \\
20 September 2008 & NBB & 106 & 1.39 \\
4 October 2008 & BB & 667 & 1.09 \\
20 August 2009 & Faint BB & 360 & 1.54 \\
24 August 2009 & BB & 463 & 1.25 \\
\hline
\end{tabular}

- We found large coefficient and small exponent in the $Z-R$ relationships in presence of $\mathrm{BB}$ while the small coefficient and large exponent in NBB conditions. The large coefficient and small exponent during the presence of $\mathrm{BB}$ are attributed to the number as well as size controlled processes while the small coefficient and large exponent are attributed only to the size controlled processes. Steiner et al. (2004) suggested that size controlled processes during the $\mathrm{BB}$ conditions are characterized by the large exponent of $Z-R$ relationships. While Sharma et al. (2009) speculated it as a number controlled process; they reported a small variation of median volume drop diameter for wide ranges of $R$ values. They utilized surface disdrometer data in their study.

- In this study, we found that the mean LWC during $\mathrm{BB}$ and NBB conditions is nearly equal to each other, both greater than the mean LWC with faint $\mathrm{BB}$ conditions. Complimentary finding was earlier reported by Martner et al. (2008), found nearly equal LWC values during $\mathrm{BB}$ and NBB conditions.

This study suggests distinct microphysical and DSD properties of low rainfall intensity during the presence and absence of BB. Also it improves the understanding of rain microphysics that may be helpful for simulation of rain DSDs during low rainfall intensity. How dynamical large scale circulations are responsible for such intermittent light rainfall that persist for many days with warmer storm height needs further study.

\section{Acknowledgements}

The Indian Institute of Tropical Meteorology is funded by Ministry of Earth Sciences, Govt of India. Authors thank Prof. B N Goswami, Director, IITM for the constant encouragement and support. They are thankful to Dr. V Gopalkrishnan, IITM for providing the OTT parsivel disdrometer data and to CloudSat science teams for their efforts and cooperation in providing the data used here. The authors are thankful to the two anonymous reviewers and the editor for their comments and suggestions to improve the manuscript.

\section{References}

Austin P M and Bemis A C 1950 A quantitative study of the 'bright band' in radar precipitation Echoes; J. Meteor. 7 145-151.

Atlas D, Ulbrich C W, Marks F D Jr, Amitai E and Williams C R 1999 Systematic variation of drop size and radarrainfall relations; J. Geophys. Res. 104 6155-6169.

Atlas D and Ulbrich C W 2000 An observationally based conceptual model of warm oceanic convective rain in the tropics; J. Appl. Meteorol. 39 2165-2181.

Atlas D and Williams C R 2003 The anatomy of a continental tropical convective storm; J. Atmos. Sci. 60 3-15.

Battan L J 1973 Radar observations of the atmosphere, The University of Chicago Press, Chicago.

Cifelli R and Rutledge S A 1994 Vertical motion structure in maritime continent mesoscale convective systems: Results from a 50-MHz profiler; J. Atmos. Sci. 51 2631-2652.

Fabry F and Zawadzki I 1995 Long-term radar observations of the melting layer of precipitation and their interpretation; J. Atmos. Sci. 52 838-851.

Glickman T S 2000 Glossary of Meteorology, 2nd edn, Amer. Meteor. Soc., 855p.

Gray W R, Cluckie I D and Griffith R J 2001 Aspects of melting and the radar bright band; Meteorol. Appl. 8 371-379.

Houze R A Jr 1993 Cloud Dynamics, Academic Press, 573p.

Houze R A Jr 1997 Stratiform precipitation in regions of convection: A meteorological paradox?; Bull. Am. Meteor. Soc. 78 2179-2196.

Huggel A W, Schmid W and Waldvogel A 1996 Rain drop size distribution and radar bright band; J. Appl. Meteorol. 35 1688-1701. 
Jameson A R and Kostinski A B 2000 Fluctuation properties of precipitation. Part VI: Observations of hyperfine clustering and drop size distribution structures in three-dimensional rain; J. Atmos. Sci. 57 373-388.

Kingsmill D E, Neiman P J, Ralph F M and White A B 2006 Synoptic and topographic variability of northern California precipitation characteristics in landfalling winter storms observed during CALJET; Mon. Weather Rev. 134 2072-2094.

Kirankumar N V P, Rao T N, Radhakrishna B and Rao D N 2008 Statistical characteristics of raindrop size distribution in southwest monsoon season; J. Appl. Meteorol. Clim. 47 576-590.

Klaassen W 1988 Radar observations and simulation of the melting layer of precipitation; J. Atmos. Sci. 45 3741-3753.

Konwar M, Sarma D K, Sharma S and Das J 2006 Shape of the raindrop size distributions and classification of rain type at Gadanki; Indian J. Radio Space Phys. 35 360-367.

Kunz M 1998 Niederschlagsmessungen mit einem vertikal ausgerichteten K-Band FM-CW-Dopplerradar. Diplomarbeit (Diploma thesis), Institut für Meteorologie und Klimaforschung, Universität Karlsruhe, 95p.

Lhermitte R M and Atlas D 1963 Doppler fall speed and particle growth in stratiform precipitation; Proc. 10th Wea. Radar Conf., Amer. Meteor. Soc., pp. 297-302.

List R 1988 A linear radar reflectivity-rainrate relationship for steady tropical rain; J. Atmos. Sci. 45 3564-3572.

Löffler-Mang M, Kunz M and Schmid W 1999 On the performance of a low-cost K-band doppler radar for quantitative rain measurement; J. Atmos. Ocean. Tech. 16 379-387.

Löffler-Mang M and Joss J 2000 An optical disdrometer for measuring size and velocity of hydrometeors; J. Atmos. Ocean. Tech. 17 130-139.

Maki M, Keenan T D, Sasaki Y and Nakamura K 2001 Characteristics of the raindrop size distribution in tropical continental squall lines observed in Darwin, Australia; J. Appl. Meteorol. 40 1393-1412.

Marshall J S and Palmer W M 1948 The distribution of raindrops with size; J. Meteor. 5 165-166.

Martner B E, Yuter S E, White A B, Matrosov S Y, Kingsmill D E and Ralph F M 2008 Raindrop size distributions and rain characteristics in California coastal rainfall for periods with and without a radar bright band; J. Hydrometeor. 9 408-425.

Nemeth K and Löffler-Mang M 2006 OTT-parsivelenhanced precipitation identifier and new generation of present weather sensor, 4th ICEAWS Conference, Lisboa, $8 p$.

Peters G, Fischer B and Andersson T 2002 Radio observations with a vertically looking Micro Rain Radar (MRR); Boreal Env. Res. 7 353-362.

Peters G, Fischer B, Münster H, Clemens M and Wagner A 2005 Profiles of raindrop size distributions by micro rain radars; J. Appl. Meteorol. 44 1930-1949.

Peters G, Fischer B and Clemens M 2010 Rain attenuation of radar echoes considering finite-range resolution and using drop size distributions; J. Atmos. Oceanic Technol. 27 829-842.

Rao T N, Rao D N and Raghavan S 1999 Tropical precipitating system observed with Indian MST Radar; Radio Sci. 34 1125-1139.

Rao T N, Rao D N, Mohan K and Raghavan S 2001 Classification of tropical precipitating systems and associated $Z-R$ relationships; J. Geophys. Res. 106 17,699-17,711.
Rogers R R, Zawadzki I and Gossard E E 1991 Variation with altitude of the drop-size distribution in steady light rain; Quart. J. Roy. Meteor. Soc. 117 1341-1369.

Sasi Kumar V, Sampath S, Vinayak P V S S K and Harikumar R 2007 Rainfall intensity characteristics at coastal and high altitude stations in Kerala; J. Earth Syst. Sci. 116(5) 451-463.

Sharma S, Konwar M, Sarma D K, Kalapureddy M C R and Jain A R 2009 Characteristics of rain integral parameters during tropical convective, transition and stratiform rain at Gadanki and its application in rain retrieval; J. Appl. Meteorol. Clim. 48 1245-1266.

Steiner M and Smith J A 1998 Convective versus stratiform rainfall: An ice-microphysical and kinematic conceptual model; Atmos. Res. 47-48 317-326.

Steiner M, Smith J A and Uijlenhoet R 2004 A microphysical interpretation of radar reflectivity-rain rate relationships; J. Atmos. Sci. 61 1114-1131.

Stephens G L, Vane D, Boain R, Mace G, Sassen K, Wang Z, Illingworth A, O'Connor E, Rossow W, Durden S, Miller $\mathrm{S}$, Austin R, Benedetti A, Mitrescu C and Cloud-Sat Science Team 2002 The CloudSat mission and the A-Train: A new dimension of space-based observations of clouds and precipitation; Bull. Am. Meteor. Soc. 83 1771-1790.

Stewart R E, Marwitz J D, Pace J C and Carbone R E 1984 Characteristics through the melting layer of stratiform clouds; J. Atmos. Sci. 41 3227-3237.

Testud J, Oury S, Black R A, Amayenc P and Dou X 2001 The concept of 'normalized' distribution to describe raindrop spectra: A tool for cloud physics and cloud remote sensing; J. Appl. Meteorol. Clim. 40 1118-1140.

Tridon F, Van Baelen J and Pointin Y 2011 Aliasing in micro rain radar data due to strong vertical winds; Geophys. Res. Lett. 38, doi: 10.1029/2010GL046018.

Tokay A and Short D A 1996 Evidence from tropical raindrop spectra of the origin of the rain from stratiform versus convective clouds; J. Appl. Meteorol. 35 506-531.

Ulbrich C W and Atlas D 2007 Microphysics of rain drop size spectra: Tropical continental and maritime storms; J. Appl. Meteorol. Clim. 46 1777-1791.

White A B, Gottas D J, Strem E T, Ralph F M and Neiman P J 2002 An automated brightband height detection algorithm for use with doppler radar spectral moments; J. Atmos. Oceanic Technol. 19 687-697.

White A B, Neiman P J, Ralph F M, Kingsmill D E and Persson P O G 2003 Coastal orographic rainfall processes observed by radar during the California Land-Falling Jets Experiment; J. Hydrometeorol. 4 264-282.

Williams C R, Ecklund W L and Gage K S 1995 Classification of precipitating clouds in the tropics using $915 \mathrm{MHz}$ wind profilers; J. Atmos. Oceanic Technol. 12 996-1012.

Willis P T and Heymsfield A J 1989 Structure of the melting layer in mesoscale convective system stratiform precipitation; J. Atmos. Sci. 46 2008-2025.

Yuter S E, Kingsmill D E, Nance L B and Löffer-Mang M 2006 Observations of precipitation size and fall speed characteristics within coexisting rain and wet snow; J. Appl. Meteorol. Clim. 45 1450-1464.

Zawadzki I and Antonio Agostinho M de 1988 Equilibrium raindrop size distribution in tropical rain; J. Atmos. Sci. $453452-3459$.

Zawadzki I, Szyrmer W, Bell C and Fabry F 2005 Modeling of the melting layer, Part III: The density effect; $J$. Atmos. Sci. 62 3705-3723. 